Sow prolificacy and piglet survival were not affected by the pregnancy diet. In contrast, the mean live weight of piglets was higher in the control group than in the other ones, especially at weaning (on an average for the two cycles : $5.5,5.0,4.7$ and $4.8 \mathrm{~kg}$ in the control, barley, wheat and maize groups, respectively) and at 35 days of age $(7.5,6.3,6.4$ and $6.3 \mathrm{~kg}$ ). Feeding diets containing $96 \%$ cereals during pregnancy reduced the development of body reserves and affected milk production during lactation. These effects particularly marked with maize may be attributed to the lysine deficiency of cereals.

Estimation of changes in the sow body composition during pregnancy showed that the lower gain of sows fed the experimental diets were due to a lower muscle gain, especially in the maize group, whereas fat deposition was not affected. On the other hand, the pregnancy weight gain decrease between the 1st and the 2nd cycle whatever the diet (mean difference between the first and second pregnancy : $8 \mathrm{~kg}$ for total weight gain and $9 \mathrm{~kg}$ for net weight gain) was due to a lower fat deposition. It is explained by higher energy maintenance requirements of heavier animals. Therefore, energy requirements during pregnancy increase with parity number.

\title{
Utilization of spring peas by the sow during pregnancy and lactation
}

\author{
F. GATEL, G. BURON, M. LEUILLET
}

I.T.C.F., 8, avenue du Président-Wilson, 75116 Paris

Utilization of spring peas (Pisum sativum) of the variety "Amino " was tested in 137 sows totalizing 536 litters distributed over 7 cycles. Control animals were fed diets without peas including cereals, soybean meal, bran and fish meal. They were compared to animals fed a diet including $16 \%$ peas during pregnancy and $24 \%$ during lactation (peas replacing cereals and soyabean meal).

Diets including peas were well ingested. Net pregnancy weight gain was similar whatever the diet, whereas weight losses during lactation were $6 \%$ higher in the pea-fed group. Weight change of sows was similar with the two dietary treatments. On an average, there was no difference in prolificacy between the two groups of animals. Birth weight and mortality of suckled piglets were similar in both groups. Growth rate of suckled piglets was slightly higher with pea-based diets (216 versus $210 \mathrm{~g} /$ day). Culling rate was similar in both groups. It was concluded that the incorporation of 16 and $24 \%$ spring peas into gestation and lactation diets did not affect the reproductive performance or life of sows.

\section{Effects of feeding gilts with normal or low glucosinolate rapeseed meal on reproductive performance}

\author{
M. ETIENNE, J.Y. DOURMAD
}

INRA, Station de Recherches Porcines, Saint-Gilles, 35590 L'Hermitage

Effects of feeding normal (cv. Jet Neuf) or low glucosinolate (cv. Tandem) winter rapeseed meal on reproductive performance were investigated in 107 Large White gilts. After mating, females were fed diets with $13.5 \%$ soyabean meal (control group) or $20 \%$ Jet Neuf (Jet Neuf group) or Tandem (Tandem group) rapeseed meal as sole protein concentrate. During a 3-week lactation, half the control gilts were fed the Jet Neuf diet and half the Jet Neuf and Tandem groups were fed the control diet. The other animals received the same diet as during pregnancy. Daily feed intake was $2.3 \mathrm{~kg}$ in pregnancy and $4 \mathrm{~kg}$ in lactation. All gilts were laparotomized 40 days post-mating to measure embryonic mortality. Eight gilts per group were slaughtered at 111 days of gestation. Thyroids of the dams and of their foetuses were weighed. Thyroid weight was also measured in three piglets per litter sacrificed at weaning.

Feeding diets containing $20 \%$ normal rapeseed meal increased by $65 \%$ the thyroid weight of gilts. This gland was not affected in the Tandem group. Thyroid hypertrophy was much more 